\title{
Dielectric and microstructural behaviour of strontium titanate borosilicate glass ceramic system
}

\author{
O P THAKUR, DEVENDRA KUMAR, OM PARKASH ${ }^{\dagger}$ and \\ LAKSHMAN PANDEY ${ }^{\dagger \dagger}$ \\ Department of Ceramic Engineering, ${ }^{\dagger}$ School of Materials Science and Technology, Institute \\ of Technology, Banaras Hindu University, Varanasi 221005 , India \\ ${ }^{+}$Department of Post-graduate Studies and Research in Physics, Rani Durgavati Vish- \\ wavidyalaya, Jabalpur 482001 , India \\ MS received 15 May 1995; revised 11 July 1995
}

\begin{abstract}
SrO} \cdot \mathrm{TiO}_{2}\right)-35\left(2 \mathrm{SiO}_{2} \cdot \mathrm{B}_{2} \mathrm{O}_{3}\right)$ wt $\%$ glass was synthesized. Differential thermal analysis study shows one exothermic peak which shifts towards higher temperature with increasing heating rate. Glass ceramics prepared by controlled crystallization of strontium titanate borosilicate glass produce uniform distribution of crystallites in a glassy matrix. Attempt was made to crystallize strontium titanate phase in this glass ceramic. Different phases precipitated out during ceramization have been identified by X-ray diffraction. It appears that due to high reactivity of $\mathrm{SrO}$ with $\mathrm{B}_{2} \mathrm{O}_{3}$, strontium borate crystallizes as principal phase followed by $\mathrm{TiO}_{2}$ (rutile) and $\mathrm{Sr}_{3} \mathrm{Ti}_{2} \mathrm{O}_{7}$ phases. Dielectric constant of these glass ceramics was observed to be more or less temperature independent over wide range of temperatures with low values of dielectric constant and dissipation factor.
\end{abstract}

Keywords. Glass ceramics; microstructure; dielectric behaviour.

\section{Introduction}

Glass ceramics, a type of polycrystalline material prepared by controlled crystallization of glass, were invented as a kind of material whose mechanical properties were superior to those of their parent glasses (Mc Millan 1979). Microstructure of the typical glass ceramic is described as a homogeneous, pore free, fine crystallites embedded in residual glassy matrix. The characteristics of glass ceramic microstructure with a suitable choice of crystallite phase constituents and amount of glassy phase impart wide scope for the optimization of dielectric properties. Accordingly, several perovskite and ferroelectric phases were precipitated in glassy matrix such as $\mathrm{BaTiO}_{3}(\mathrm{Herczog} 1984)$, $\mathrm{PbTiO}_{3}$ (Kokubo 1969; Parkash Om et al 1986; Mandal et al 1987) and $\mathrm{NaNbO}_{3}$ etc (Layton and Herczog 1967).

Strontium titanate is a prototype ceramics with perovskite structure and is a candidate for technological applications, possibly as a capacitor owing to its incipient ferroelectric properties. Major work was carried out on strontium titanate aluminosilicate glass ceramic system (Lawless 1971, 1972a,b; Swartz and Bhalla 1986; Swartz et al 1988a,b) which has found application in cryogenic capacitive temperature sensors.

It is well known that $\mathrm{B}_{2} \mathrm{O}_{3}$ can combine to form good glasses with an unlimited number of other components. Boron oxide contributes many useful properties to finished borosilicate glass, such as (i) lowers thermal expansion, making the glass more resistance to heat, (ii) improves chemical durability, (iii) enhance melting of the more refractory batch constituents and (iv) lowers the melting point to accelerate the melting reactions (Krogh-Moe 1969; Furukawa and White 1980; Walrafen et al 1980; Smith 
1986). No studies on crystallization and dielectric behaviour of strontium titanate borosilicate glass ceramic were reported. Hence the present work was undertaken.

In the present investigation, attempts have been made to understand the crystallization, microstructural and dielectric behaviour of strontium titanate borosilicate glass ceramic system.

\section{Experimental}

All the materials used viz. $\mathrm{SrCO}_{3}, \mathrm{TiO}_{2}, \mathrm{SiO}_{2}$ and $\mathrm{H}_{3} \mathrm{BO}_{3}$ were of chemically pure grade (purity $>99 \%$ ). Batches weighing $25 \mathrm{~g}$ in appropriate amount $65 \mathrm{wt} \%\left[\mathrm{SrO} \cdot \mathrm{TiO}_{2}\right]-35$ $\mathrm{wt} \%\left[2 \mathrm{SiO}_{2} \cdot \mathrm{B}_{2} \mathrm{O}_{3}\right]$ were mixed in an agate mortar using acetone as a grinding medium. The dry and homogeneous mixture was melted in high grade alumina crucible for $1 \mathrm{~h}$ at $1500 \mathrm{~K}$ in an electrically heated furnace. The molten batch was stirred periodically to homogenize the melt and cooled rapidly by pouring the glass on to an aluminium plate and pressing with another plate on top of the molten glass. The glass samples obtained were annealed at $673 \mathrm{~K}$ for $2 \mathrm{~h}$. The annealed samples were furnace cooled.

The amorphosity of glass powder was checked by X-ray diffraction. DTA scans were recorded with different heating rates using NETZSH thermal analyzer model STA 409 to find the glass transition $T_{\mathrm{g}}$ and crystallization temperature $T_{c}$. Glasses were heat treated in the temperature range $1073 \mathrm{~K}-1223 \mathrm{~K}$. Crystalline phases in glass ceramics were identified and characterized by recording their X-ray diffraction patterns with a Rich Seifert X-ray diffractometer Model ID-3000 using $\mathrm{Cu}-\mathrm{K} \alpha$ radiation. X-ray diffraction patterns (XRD) were compared with standard $d$-values from JCPDS files for different constituting phases. Samples were polished and etched using $2 \% \mathrm{HF}$ and $5 \%$ $\mathrm{HCl}$ for $30 \mathrm{sec}$. Microstructures of these etched samples were observed using SEM stereoscan 250 MK III (Cambridge Instruments Ltd., UK) scanning electron microscope after deposition of Au-Pd film. For dielectric measurement, glass samples were polished on both sides. Conducting silver paint was applied on both sides and fired at $973 \mathrm{~K}$ for $5 \mathrm{~min}$ to make good electrical contacts. Dielectric measurements were carried out using an HP Impedance Analyzer (Model 4192A LF) in the frequency range $1 \mathrm{kHz}$ to $100 \mathrm{kHz}$ from room temperature to $530 \mathrm{~K}$.

\section{Results and discussion}

DTA for glass at various heating rates $\left(5,10,15^{\circ} \mathrm{C} / \mathrm{min}\right)$ are shown in figure 1 . These plots show glass transition temperature around $705^{\circ} \mathrm{C}$ and crystallization temperature in the range $900-950^{\circ} \mathrm{C}$. The onset of crystallization is $850^{\circ} \mathrm{C}$. Different heating rates influence the exothermic peaks drastically. It was observed that crystallization peak temperature increased with increase in the heating rate of glass powder (Marotta et al 1982).

$\mathrm{X}$-ray diffraction study reveals the principal crystalline phases appearing from all the glass ceramic samples such as strontium borate, rutile and $\mathrm{Sr}_{3} \mathrm{Ti}_{2} \mathrm{O}_{7}$. From X-ray diffraction study it seems that the growth rate of rutile phase increases little faster than other phases like $\mathrm{Sr}_{2} \mathrm{~B}_{2} \mathrm{O}_{5}$ and $\mathrm{Sr}_{3} \mathrm{Ti}_{2} \mathrm{O}_{7}$ with increasing temperature. At low temperature, growth of $\mathrm{Sr}_{2} \mathrm{~B}_{2} \mathrm{O}_{5}$ and $\mathrm{Sr}_{3} \mathrm{Ti}_{2} \mathrm{O}_{7}$ is larger when glass is held for longer duration of time. Phase formation as indexed by peak position resembles well with the 


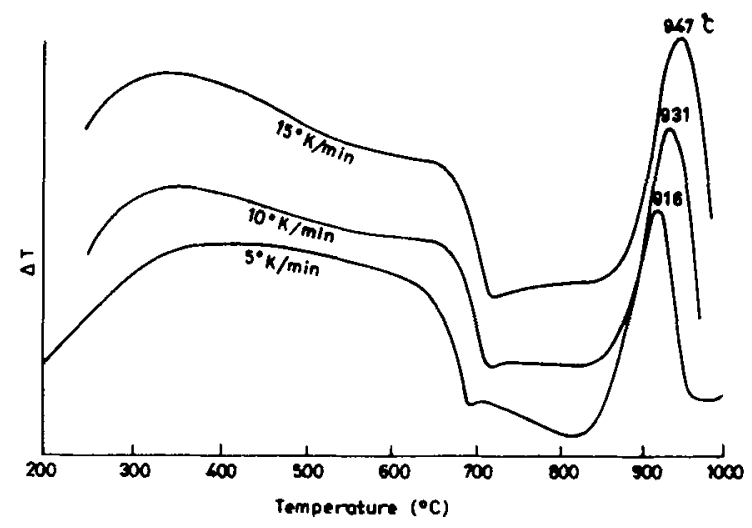

Figure 1. DTA pattern of base glass with different heating rates.

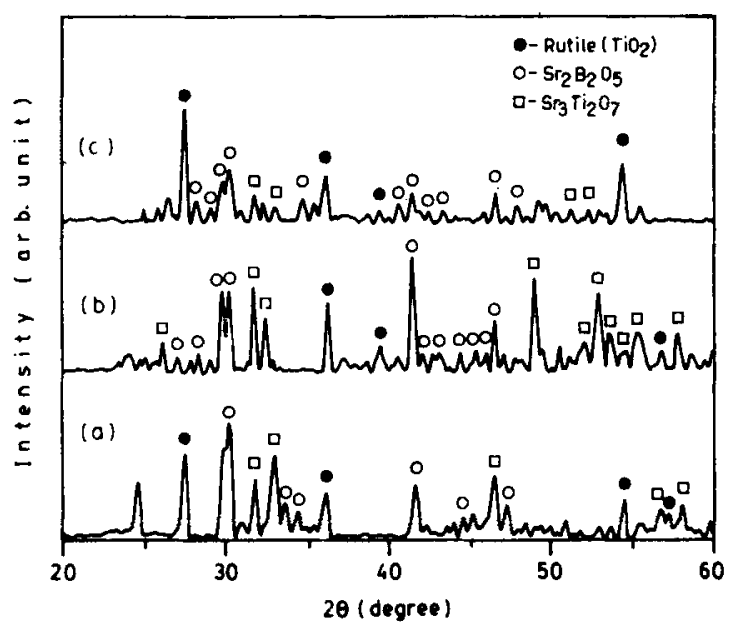

Figure 2. XRD patterns for glass ceramic crystallized at (a) $900^{\circ} \mathrm{C} / 12 \mathrm{~h}$, (b) $905^{\circ} \mathrm{C} / 48 \mathrm{~h}$ and (c) $950^{\circ} \mathrm{C} / 3 \mathrm{~h}$.

micrographs of corresponding glass ceramic samples. Some unidentified peaks were also observed. Some of the glasses were heated at $500^{\circ} \mathrm{C}$ for $1 \mathrm{~h}$ prior to crystallization. These glasses were crystallized at $900^{\circ} \mathrm{C}$ and $950^{\circ} \mathrm{C}$ for $3 \mathrm{~h}$ which show the formation of rutile phase in a major amount as shown in figure 2 . However, glasses which have been heat treated without exposing at $500^{\circ} \mathrm{C}$ for $1 \mathrm{~h}$ mainly consist of strontium borate as a primary phase as illustrated in figure 3 .

In this glass ceramic system, phase separation in glasses was not observed as evidenced from the uniform distribution of crystallites in glassy matrix.

For the glasses heat treated at $800^{\circ} \mathrm{C}$ for $1 \mathrm{~h}$, micrograph (figure $4 \mathrm{a}$ ) reveals tiny crystallites of $\mathrm{Sr}_{3} \mathrm{Ti}_{2} \mathrm{O}_{7}$ which started appearing around the borate (acicular-type crystallites) phase. Figure $4 \mathrm{~b}$ illustrates the microstructure for the glass ceramic heat treated at $860^{\circ} \mathrm{C}$ for $3 \mathrm{~h}$ which reveals the dense microstructure as the rate of growth of each constituting phases which increases with respect to temperature and holding time. As the temperature is increased to $905^{\circ} \mathrm{C}$, submicron crystallites interconnected with each other were found as evidenced from figure $4 \mathrm{c}$. Figures $4 \mathrm{~d}-\mathrm{e}$ clearly depict that 


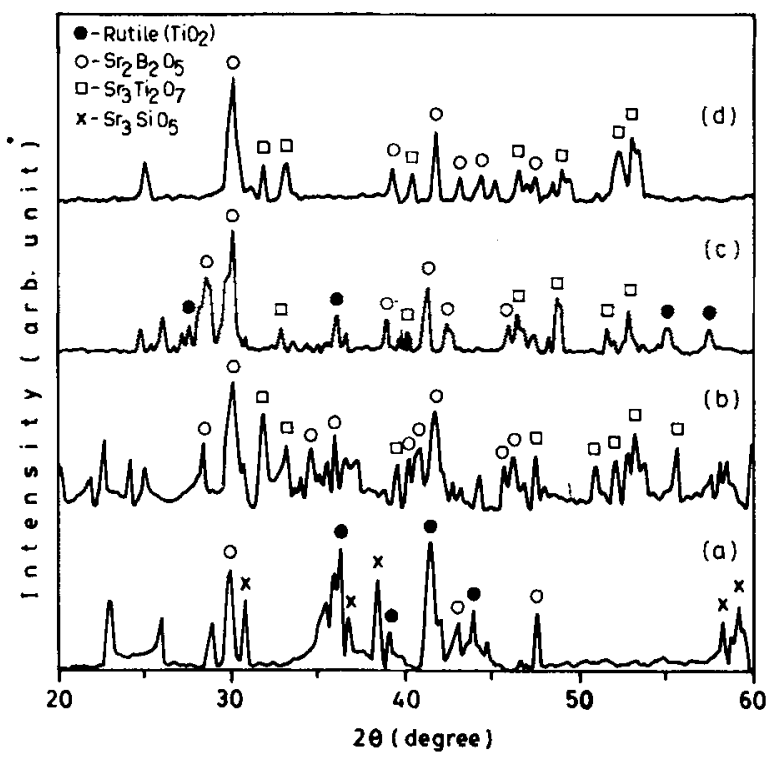

Figure 3. XRD patterns for glass ceramic crystallized at (a) $800^{\circ} \mathrm{C} / 1 \mathrm{~h}$, (b) $800^{\circ} \mathrm{C} / 3 \mathrm{~h}$, (c) $860^{\circ} \mathrm{C} / 1 \mathrm{~h}$ and (d) $860^{\circ} \mathrm{C} / 3 \mathrm{~h}$.

some phases like $\mathrm{Sr}_{3} \mathrm{Ti}_{2} \mathrm{O}_{7}, \mathrm{Sr}_{2} \mathrm{~B}_{2} \mathrm{O}_{5}$ started growing slowly and filling the intermediate gap which shows complete crystallization if the glass samples were exposed for longer duration at crystallization temperature. Figure $4 \mathrm{~d}$ shows the star-like pattern. Growth of crystallites from the central point forming star-like pattern in these glass ceramics may be described as follows: During initial stage of crystallization, particles of size 500-1000 $\AA$ in diameter appear in the glass. These particles are agglomerate of very fine crystallites of diam $100 \AA$ or less. These fine crystallites serve as nucleus and growth of star-like crystal configuration takes place. As the crystallization temperature is raised to $950^{\circ} \mathrm{C}$ (figure $4 \mathrm{f}$ ), there is no major change seen in morphology of this glass ceramic sample except little growth in crystallite size. In the initial stage of crystallization formation of fine crystallites of submicron size was observed while for the longer duration of crystallization larger crystals (2-3 $\mu \mathrm{m}$ size), well interconnected and dense microstructure were observed. From microstructural study it was observed that all micrographs show uniform distribution of precipitated crystals in the strontium titanate borosilicate glass ceramic system.

The variation of dielectric constant and dissipation factor of samples crystallized at different temperatures for different time as a function of temperature at $1 \mathrm{kHz}, 10 \mathrm{kHz}$ and $100 \mathrm{kHz}$ is shown in figures $5-7$.

Figure 5 shows the variation of dielectric constant and dissipation factor with temperature for glass ceramic crystallized at $800^{\circ} \mathrm{C}$ for $3 \mathrm{~h}$. Values of dielectric constant and dissipation factor are in the range $23-30$ and $0.005-0.155$ respectively. Low value of dielectric constant may be due to major amount of glassy phase in glass ceramic samples. Variation of dissipation factor with temperature is similar to that of dielectric behaviour. Glass sample heat treated at $860^{\circ} \mathrm{C}$ for $1 \mathrm{~h}$ illustrates almost temperature independent behaviour of dielectric constant over the large range of temperatures (figure 6). The temperature coefficient of dielectric constant is approximately calculated to be $8.57 \times 10^{-3} / \mathrm{C}$. This can be understood in terms of small grain size and restraining 
effect of rigid glassy matrix. Values of dielectric constant and dissipation factor were observed in the range $55-57$ and $0.002-0.02$ respectively.

When the glass sample is given longer duration heat treatment at higher temperature $\left(905^{\circ} \mathrm{C}\right.$ ), $\mathrm{Sr}_{3} \mathrm{Ti}_{2} \mathrm{O}_{7}$ forms in majority followed by $\mathrm{Sr}_{2} \mathrm{~B}_{2} \mathrm{O}_{5}$ and $\mathrm{TiO}_{2}$ (rutile) phase. Figure 7 shows the characteristics of dielectric constant and dissipation factor with temperature of glass ceramic sample heat treated at $905^{\circ} \mathrm{C}$ for $48 \mathrm{~h}$. It is interesting to note that dielectric constant with respect to temperature changes very little below a particular temperature and thereafter rises rapidly. The increment in dielectric
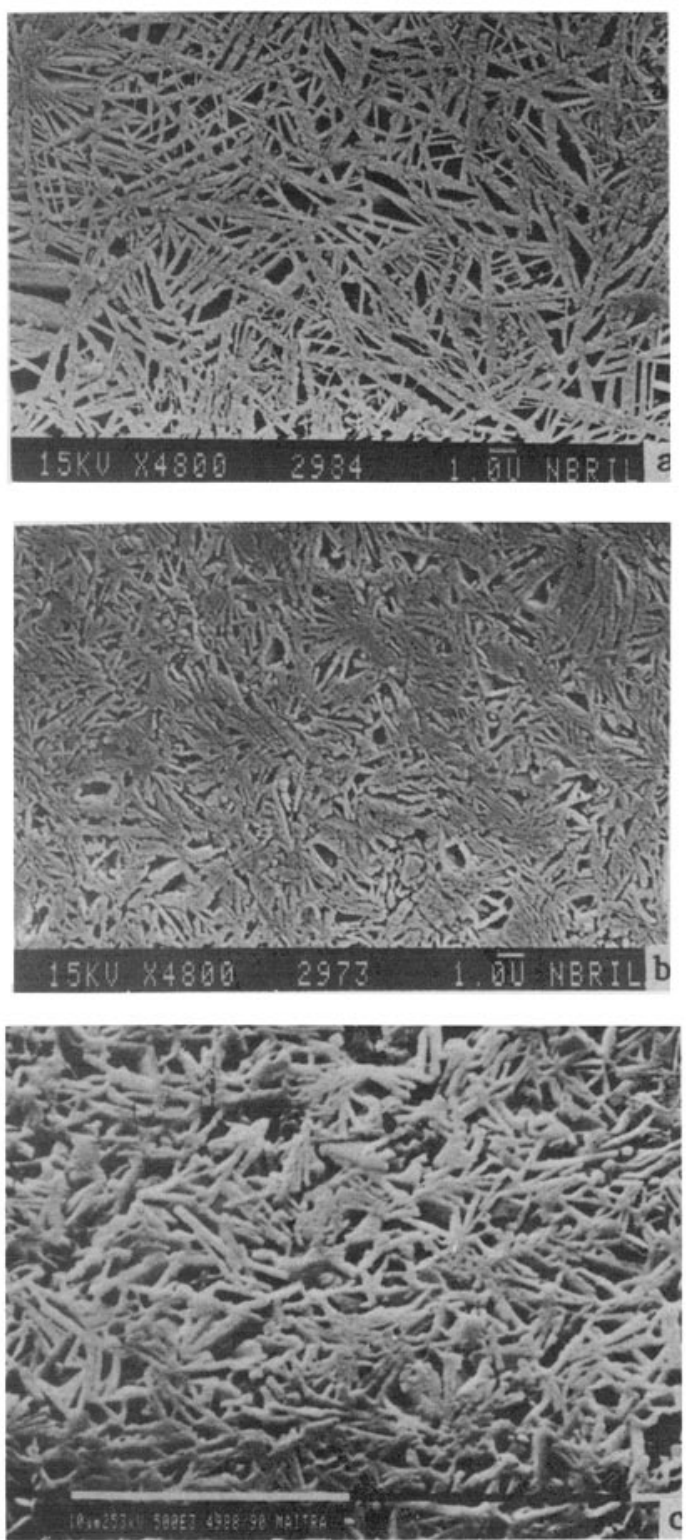

Figure 4. a-c. 

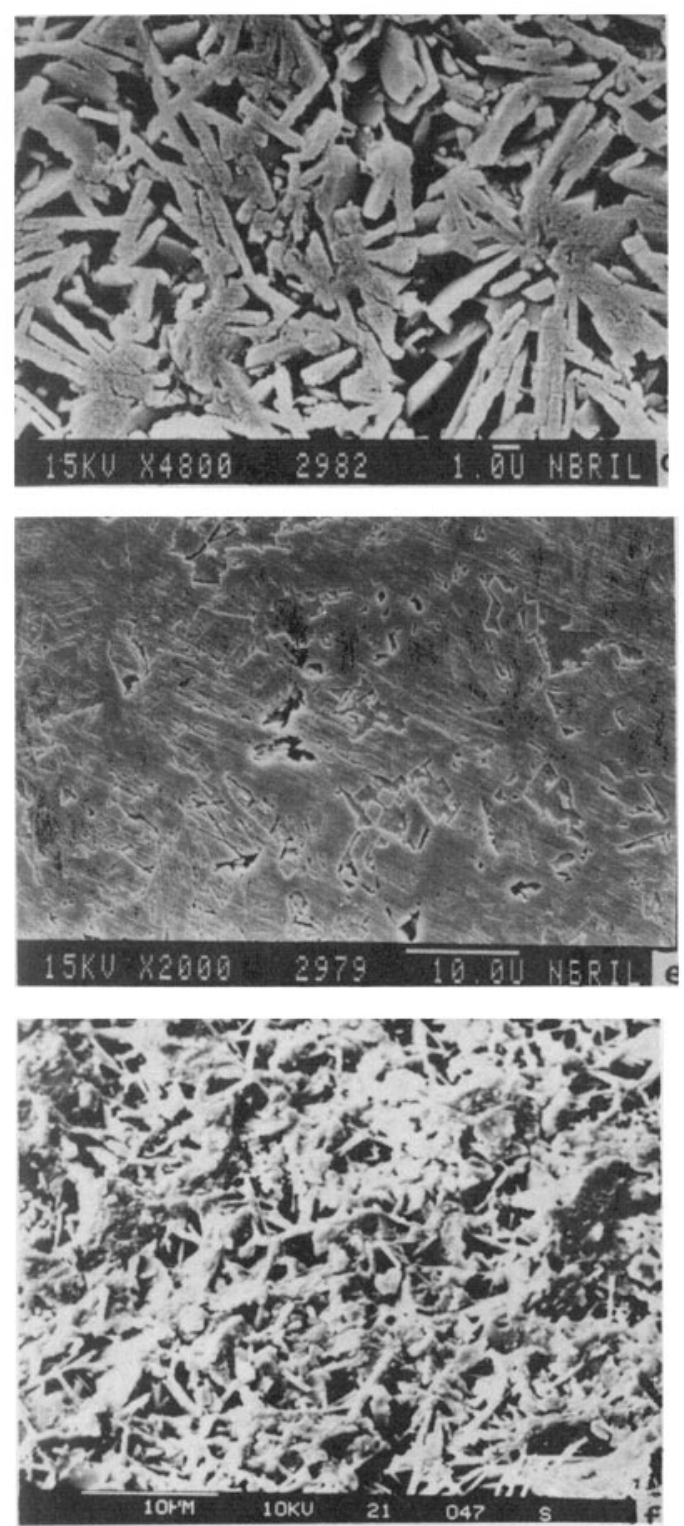

Figure 4. Scanning electron micrographs of glass ceramic crystallized at (a) $800^{\circ} \mathrm{C} / 1 \mathrm{~h}$, (b) $860^{\circ} \mathrm{C} / 3 \mathrm{~h}$, (c) $905^{\circ} \mathrm{C} / 3 \mathrm{~h}$, (d) $905^{\circ} \mathrm{C} / 24 \mathrm{~h}$, (e) $905^{\circ} \mathrm{C} / 48 \mathrm{~h}$ and (f) $950^{\circ} \mathrm{C} / 3 \mathrm{~h}$.

constant is less at higher frequency and increases with decreasing frequency. The dissipation factor also increases sharply beyond this particular point. Frequency dispersion at lower frequency and higher temperature for dielectric constant and dissipation factor may be attributed to the space charge polarization.

The dielectric constant and loss behaviour for all of these glass ceramic samples could be understood in terms of different crystalline and relative amount of the constituent phases which develop during ceramization. 


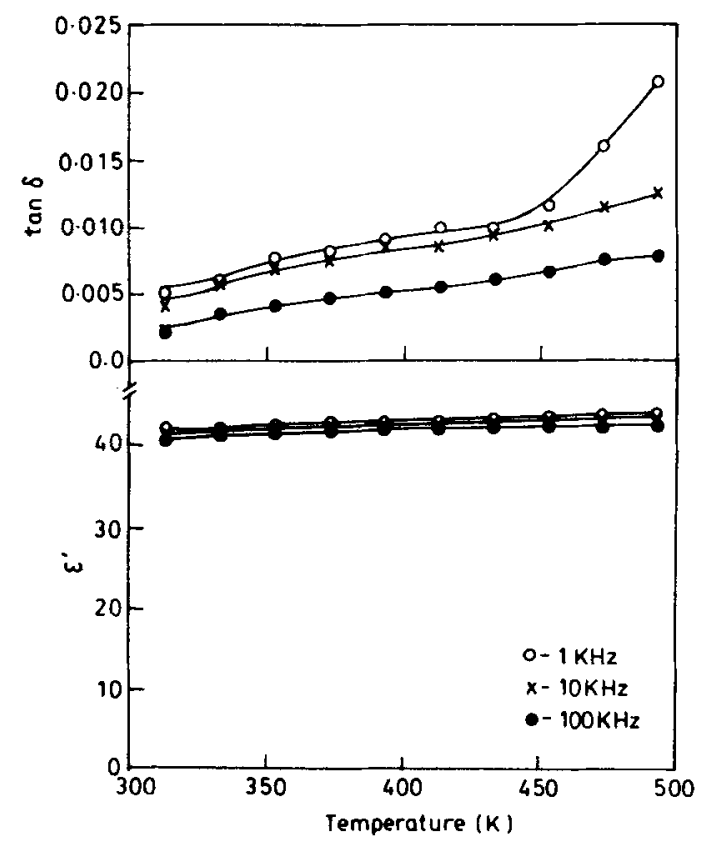

Figure 5. Variation of dissipation factor $(\tan \delta)$ and dielectric constant $\left(\varepsilon^{\prime}\right)$ with temperature of glass ceramic crystallized at $800^{\circ} \mathrm{C}$ for $3 \mathrm{~h}$.
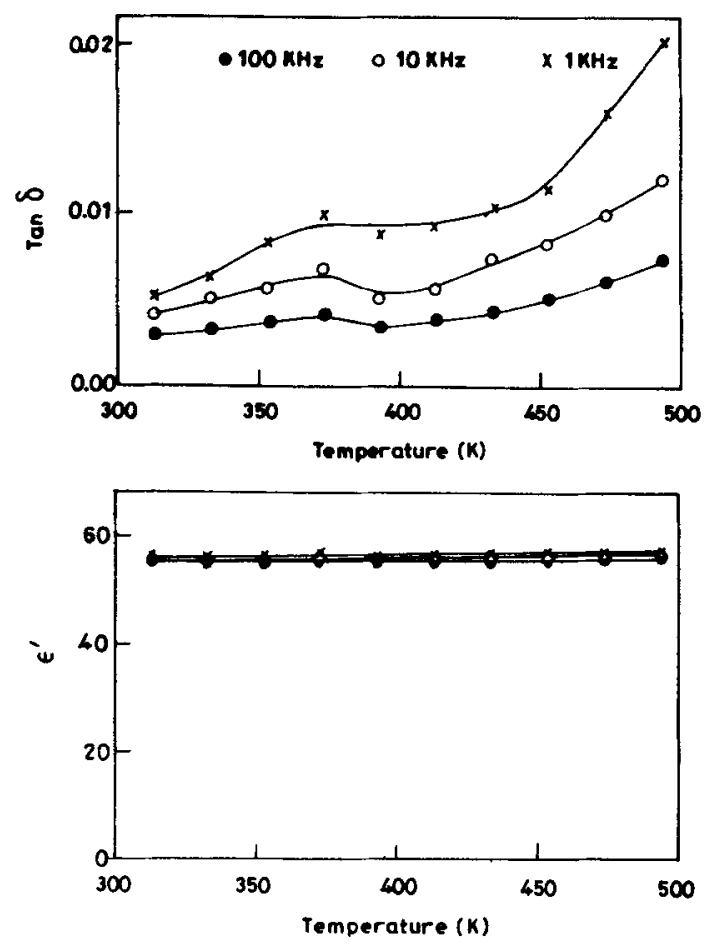

Figure 6. Variation of dissipation factor $(\tan \delta)$ and dielectric constant $\left(\varepsilon^{\prime}\right)$ with temperature of glass ceramic crystallized at $860^{\circ} \mathrm{C}$ for $1 \mathrm{~h}$. 

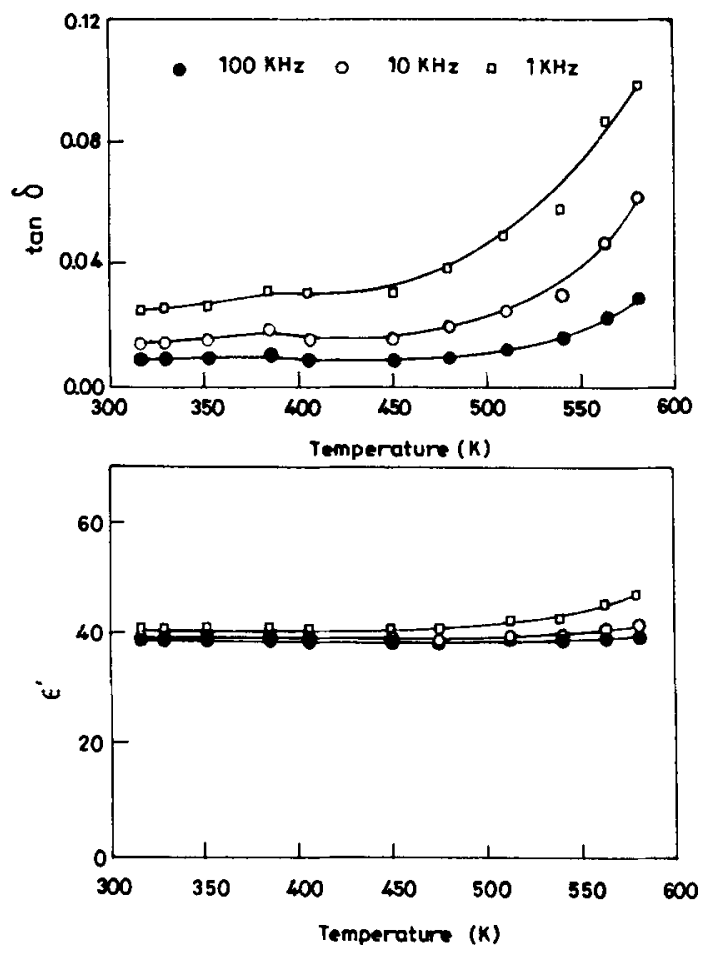

Figure 7. Variation of dissipation factor $(\tan \delta)$ and dielectric constant $\left(\varepsilon^{\prime}\right)$ with temperature of glass ceramic crystallized at $905^{\circ} \mathrm{C}$ for $48 \mathrm{~h}$.

\section{Conclusions}

The following conclusions drawn from these investigations are:

(i) We could not find strontium titanate in this composition because of the higher reactivity of constituting components.

(ii) Crystallization study shows the formation of $\mathrm{Sr}_{2} \mathrm{~B}_{2} \mathrm{O}_{5}$ as a major phase followed by rutile and $\mathrm{Sr}_{3} \mathrm{Ti}_{2} \mathrm{O}_{7}$ etc.

(iii) Uniform distribution of crystallites in glassy matrix was observed which supports in the reproducibility of dielectric properties in respective glass ceramic samples.

(iv) The role of boron oxide in this system lowers the glass melting temperature and hence the crystallization temperature of the glass.

(v) It is possible with the variation of heat treatment schedule to get material of desired properties. Glass ceramic sample heat treated at $860^{\circ} \mathrm{C}$ for $1 \mathrm{~h}$ could be used as the material where dielectric thermal stability and lower values of dielectric constant and dissipation factor are required.

\section{Acknowledgements}

Financial assistance from CSIR, New Delhi is gratefully acknowledged. One of the authors(OPT) is thankful to the Department of Atomic Energy, Bombay for a research 
fellowship. We are thankful to the Director, Regional Sophisticated Instrumentation Centre (RSIC), Nagpur for providing Electron Microscopy Facility.

\section{References}

Furukawa T and White W B 1980 Phys. Chem. Glasses 2185

Herczog A 1984 J. Am. Ceram. Soc. 67484

Kokubo T 1969 Yogyo-Kyokai-Shi 77293

Krogh-Moe J 1969 J. Non-Cryst. Solids 1269

Layton M M and Herczog A 1967 J. Am. Ceram. Soc. 50369

Lawless W N 1971 Adv. Cryogenic Eng. 16261

Lawless W N 1972a Rev. Sci. Instrum. 42561

Lawless W N 1972b US Patent 3649891

Mandal R K, Durgaprasad Ch, Parkash O and Kumar Devendra 1987 Bull. Mater. Sci. 9255

Marotta A, Buri A, Branda F and Saiello S 1982 Adv. Ceram. 4146

Mc Millan P W 1979 Glass ceramics (London: Academic Press) 2nd ed.

Parkash O, Kumar Devendra and Rajgopalan R 1986 Bull. Mater. Sci. 113

Smith R A $1986 J$. Non-Cryst. Solids 84421

Swartz S L and Bhalla A S 1986 Mater. Res. Bull. 211417

Swartz S L, Brevel E, Randall C A and Fox B H 1988a J. Mater. Sci. 233997

Swartz S L, Bhalla A S, Cross L E and Lawless W N 1988b J. Mater. Sci. 234004

Walrafen G E, Samanta S R and Krishnan P N 1980 J. Chem. Phys. 72113 